\title{
Increased gall bladder volume in primary sclerosing cholangitis
}

\author{
P C van de Meeberg, P Portincasa, F H J Wolfhagen, K J van Erpecum, \\ G P VanBerge-Henegouwen
}

\begin{abstract}
Background-The diagnosis of primary sclerosing cholangitis (PSC) requires invasive procedures such as liver biopsy and endoscopic retrograde cholangiography (ERC). Sonographic measurement of fasting gall bladder volume, which has been reported to be enlarged in PSC, could serve as a non-invasive screening test.

Methods-Fasting gall bladder volume was studied in patients with PSC $(n=24)$, primary biliary cirrhosis (PBC, $n=13)$, liver cirrhosis due to other causes $(n=18)$, ulcerative colitis $(n=15)$, and healthy controls $(n=23)$. Meal induced gall bladder emptying was studied in patients with PSC, patients with $\mathrm{PBC}$, and healthy controls.
\end{abstract}

Results-In patients with PSC gall bladder volume was greatly enlarged $\mathbf{( 7 2 . 9}$ (SEM 3.7) ml) compared with healthy controls $(25.4(1.7) \mathrm{ml}$, and patients with PBC (30.9 (2.7) ml), liver cirrhosis (31.3 $(4 \cdot 0) \mathrm{ml})$ or ulcerative colitis $(25 \cdot 8(2 \cdot 0)$ ml) $(\mathbf{p}<0.0005 v$ all). In four patients with PSC the gall bladder wall was irregularly thickened ( $>4 \mathrm{~mm}$ ) as previously described in PSC. Postprandial residual fractions (\% of fasting volume) were comparable between patients with PSC $(17 \cdot 5$ $(3 \cdot 7) \%)$ and those with PBC (23.6 (7.1\%) and healthy controls $(12 \cdot 7 \quad(2 \cdot 3) \%)$ Although gall bladder emptying seems normal, increased biliary pressure in patients with PSC cannot be excluded.

Conclusion-Apart from wall thickening, patients with PSC often present with enlargement of the gall bladder. Sonographic determination of fasting gall bladder volume may be a useful, noninvasive, and easy to perform tool in the evaluation of patients suspected of having PSC.

(Gut 1996; 39: 594-599)

Keywords: gall bladder, primary sclerosing cholangitis, cholestasis, ulcerative colitis, ultrasonography.

Primary sclerosing cholangitis (PSC) is a rare chronic liver disease of unknown aetiology, characterised by fibrosing strictures of the intrahepatic and extrahepatic bile ducts and progressive liver dysfunction. In $70 \%$ of cases the disease is associated with ulcerative colitis and, less often, with Crohn's disease. The diagnosis is based on typical histological findings (onion skin lesions) in liver tissue and the typical beading appearance of the biliary tree on endoscopic retrograde cholangiography (ERC). Most early stage patients are asymptomatic and present only with raised liver enzymes during routine blood tests. ${ }^{1}$ The prevailing reluctance to perform a liver biopsy and ERC in asymptomatic patients is understandable in view of the morbidity and mortality from these procedures. ${ }^{2}{ }^{3}$ Therefore, the diagnosis of PSC is often suspected without being confirmed. Recently, it has been shown that the hydrophilic bile salt ursodeoxycholic acid (UDCA) has beneficial effects on clinical, biochemical, and histological parameters of PSC. ${ }^{4-6}$ In primary biliary cirrhosis (PBC), another cholestatic liver disease, progression is slowed and the need for liver transplantation is reduced in patients treated with UDCA. ${ }^{7}$ These promising results suggest that early treatment, requiring an early diagnosis, is important. In this regard, a non-invasive method to detect patients at risk for PSC, especially among patients with ulcerative colitis of whom about 5\% develop PSC, would be of considerable value.

In a preliminary study, we reported that the fasting gall bladder volume is enlarged in patients with PSC. $^{8}$ Although a few studies have reported on gall bladder and cystic duct involvement in PSC, gall bladder enlargement has never been described. ${ }^{9-13}$ Wondering whether sonographic measurement of gall bladder volume could serve as a non-invasive screening test for PSC, we examined gall bladder volume in patients with PSC. Healthy persons, patients with PBC, patients with liver cirrhosis due to other causes, and patients with ulcerative colitis with normal liver biochemistry were studied as controls. In addition, gall bladder emptying in response to a meal was studied in patients with PSC or $\mathrm{PBC}$ and healthy controls.

\section{Methods}

Fasting gall bladder volume was measured in 24 patients with PSC (median age 37, range 18-49 years; men:women 17:7, body mass index (BMI) 23.9 (SD 0.6)). Sixteen patients $(67 \%)$ had concomitant inflammatory bowel disease (14 ulcerative colitis, two Crohn's disease). Bile duct lesions were found both proximal and distal to the cystic duct in 14 $(58 \%)$ patients whereas only proximal lesions were found in seven (29\%) patients on ERC. In three patients attempts to perform ERC were unsuccessful. Liver biopsies were performed in all patients and were compatible with PSC in all. All patients had biochemical 
signs of cholestasis as reflected by a serum alkaline phosphatase or $\gamma$-glutamyl transpeptidase concentration $>150 \%$, the upper level of normal, but none of the patients had overt jaundice during the study (Table). According to Ludwig et al 19 patients $(79 \%)$ had early stage disease (stage I or II), five patients (21\%) had late stage disease (stage III, $\mathrm{n}=3$; stage IV, $\mathrm{n}=2) .{ }^{1}$ Only one patient had portal hypertension (varices and splenomegaly). Twenty three healthy subjects (median age 31 , range 24-57 years; men:women 17:6, BMI 22.4 (SD $0.5)$ were studied as controls. Also studied were 15 patients with ulcerative colitis with normal liver biochemistry (ulcerative colitis controls, median age 35, range $22-57$ years; men:women 10:5, BMI 24 (SD $0 \cdot 6$ ), 13 patients with $\mathrm{PBC}$ (median age 50, range 37-71 years; men:women 4:9, BMI 25.9 (SD $1 \cdot 1)$; all with positive antimitochondrial antibodies) including two patients with cirrhosis and portal hypertension and 18 patients (median age 52, range 26-70 years; men:women 9:9, BMI 24.1 (SD 0·7) with liver cirrhosis of other aetiology (alcohol misuse, $\mathrm{n}=4$; autoimmune hepatitis, $\mathrm{n}=3$; hepatitis $\mathrm{B}$, $n=2$; hepatitis $C, n=6$; cryptogenic, $n=3$ ). Nine $(50 \%)$ patients with liver cirrhosis had signs of portal hypertension (ascites or varices). Liver biochemistry was comparable between patients with PSC and those with PBC; however, in the group of patients with liver cirrhosis of different aetiology some had normal liver enzymes (Table). None of the patients with PSC and ulcerative colitis control patients had active colitis at the time of the study. Patients with PSC were matched with ulcerative colitis control patients regarding the extent of the colitis. Colectomised patients were excluded. One ulcerative colitis control and two patients with PBC proved to have gall stones. No other disease controls and none of the healthy subjects or patients with PSC had gall stones. Since gall bladder volume can be increased during $\mathrm{UDCA}^{14}$ and decreased during cholestyramine ${ }^{15}$ treatment, these drugs were interrupted at least one month before the study. In a separate study we found only trace amounts of UDCA ( $<2 \%$ of total bile salts) in duodenal bile samples one month after interrupting UDCA treatment in five patients with PSC participating in a dose finding study (unpublished data).

Measurement of gall bladder volume was performed in the morning after an overnight fast. Subcostal sonographic images were obtained in a supine position (Scanner $250,3 \cdot 5 / 5$ $\mathrm{MHz}$ convex transducer, Pie Medical, Maastricht, The Netherlands). With five min-

Characteristics of liver biochemistry

\begin{tabular}{llllll}
\hline Patient group & $\begin{array}{l}\text { Bilirubin } \\
(\mu \mathrm{mol})\end{array}$ & $\begin{array}{l}\text { APh } \\
(\mathrm{U} /)\end{array}$ & $\begin{array}{l}\text { GGT } \\
(\mathrm{U})\end{array}$ & $\begin{array}{l}\text { AST } \\
(\mathrm{U})\end{array}$ & $\begin{array}{l}\text { ALT } \\
(\mathrm{U})\end{array}$ \\
\hline PSC (n=24) & $15 \cdot 5(1 \cdot 7)$ & $296 \cdot 5(44 \cdot 6)$ & $342 \cdot 0(53 \cdot 5)$ & $58 \cdot 3(11 \cdot 8)$ & $90 \cdot 2(17 \cdot 7)$ \\
PBC (n=13) & $10 \cdot 4(1 \cdot 5)$ & $235 \cdot 1(46 \cdot 1)$ & $314 \cdot 7(107 \cdot 7)$ & $40 \cdot 8(7 \cdot 6)$ & $49 \cdot 8(12 \cdot 4)$ \\
Liver cirrhosis (n=18) & $19 \cdot 0(3 \cdot 3)$ & $76 \cdot 8(9 \cdot 3)$ & $82 \cdot 9(11 \cdot 9)$ & $90 \cdot 8(36 \cdot 7)$ & $76 \cdot 1(34 \cdot 1)$ \\
\hline
\end{tabular}

Results are means (SEM). Upper limits of normal: bilirubin: $<17 \mu \mathrm{mol} / \mathrm{l}$; alkaline phosphatase (APh): $<93 \mathrm{U} / 1 ; \gamma$-glutamyl transpeptidase (GGT): $<46 \mathrm{U} / 1$ (male),$<29 \mathrm{U} / 1$ (female); aspartate transaminase (AST): $<30 \mathrm{U} / 1$; alanine transaminase (ALT): $<30 \mathrm{U} / 1$. ute intervals the maximum longitudinal and transversal (height and width) dimensions were measured three times and the longitudinal perimeter of the gall bladder encircled with a caliper. The volume of the gall bladder was calculated with built in software according to the sum of cylinders method. ${ }^{16}$ Fasting gall bladder volume was the mean of these three measurements. The sum of cylinders method estimates gall bladder volume more accurately than the ellipsoid ${ }^{17}$ and area-length methods ${ }^{18}$ and has recently been validated in vivo. ${ }^{19}$

Postprandial gall bladder emptying was determined in patients with PSC (except those with thickening $(>0.4 \mathrm{~mm})$ of the gall bladder wall), patients with $\mathrm{PBC}$, and healthy controls after ingestion of a mixed meal $(2815 \mathrm{~kJ}, 35 \mathrm{~g}$ fat) containing an egg, one slice of bread with cheese, sweetened yogurt, and a cup of tea. Subsequently, gall bladder volume was measured every 10 minutes during two hours. The smallest postprandial volume was considered to be the residual volume.

The protocol was approved by the ethics committee of the University Hospital Utrecht where all examinations were performed. Informed consent was obtained from each patient.

\section{DATA ANALYSIS}

Data are presented as means (SEM). For data not normally distributed, median and range are given and $\log$ transformation was used. Statistical analysis of fasting and residual gall bladder volumes was performed by analysis of variance (ANOVA) and confirmed with Fisher's least significance difference test; $\mathrm{p}<0.05$ was considered significant. Multiple regression analysis was used to compare fasting gall bladder volumes with biochemical variables.

\section{Results}

FASTING GALL BLADDER VOLUME

Fasting gall bladder volume in patients with PSC was enlarged more than twofold $(72.9$ $(13.7) \mathrm{ml}$, median $55.6 \mathrm{ml}$, range $15.4-324.7$ $\mathrm{ml})$ compared with healthy controls $(25 \cdot 4(1 \cdot 7)$ $\mathrm{ml})$, patients with PBC $(30 \cdot 9(2 \cdot 7) \mathrm{ml})$, liver cirrhosis controls $(31.3(4 \cdot 0) \mathrm{ml})$, and ulcerative colitis controls $(25 \cdot 8 \quad(2 \cdot 0) \quad \mathrm{ml})$ $(\mathrm{p}<0.0005$, PSC $v$ all; Figs 1 and 2$)$. In four patients with PSC $(16 \cdot 7 \%$, all early stage) the gall bladder wall seemed to be irregularly thickened $(>4 \mathrm{~mm})$ as previously described in patients with PSC. ${ }^{13}$ In this subgroup of patients, gall bladder volume was in the normal range $(22.0(3.3) \mathrm{ml})$. Liver cirrhosis controls with portal hypertension tended to have a smaller gall bladder volume $(27.6(4 \cdot 6) \mathrm{ml})$ than those without portal hypertension $(35 \cdot 8$ $(6 \cdot 8) \mathrm{ml}, \mathrm{NS})$.

No significant difference was found in gall bladder volume of patients with $(70 \cdot 2(12 \cdot 9)$ $\mathrm{ml}$, median $56.4 \mathrm{ml}$, range $22.9-202.0 \mathrm{ml}$ ) and without $(87.5(40.1) \mathrm{ml}$, median $58.8 \mathrm{ml}$, range $25 \cdot 5-324 \cdot 7 \mathrm{ml}$ ) bile duct strictures 


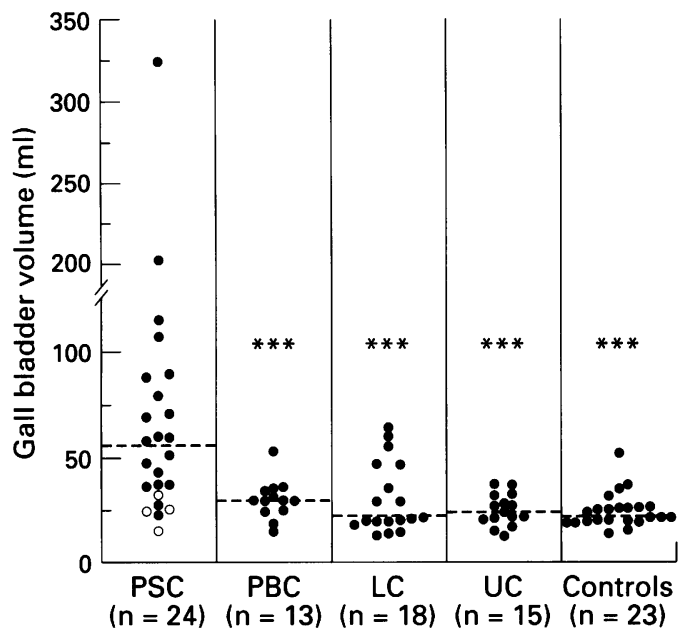

Figure 1: Individual fasting gall bladder volumes in patients with PSC, PBC, liver cirrhosis due to other causes (LC), ulcerative colitis with normal liver biochemistry (UC), and healthy subjects (controls). Open symbols (O) indicate patients with PSC with a thickened gall bladder wall $(>4 \mathrm{~mm})$. Dotted lines indicate median gall bladder volume in each group. ${ }^{\star * *} p<0.0005$.

distally from the cystic duct. In one patient with a dominant stricture of the common bile duct, gall bladder volume was $108.0 \mathrm{ml}$ before and $106.1 \mathrm{ml}$ two days after placement of an endoprosthesis.

In patients with late stage disease, gall bladder volume tended to be larger than in patients with early stage disease $(100 \cdot 7(25 \cdot 8)$ $\mathrm{ml} v 65 \cdot 5(15 \cdot 8) \mathrm{ml}, \mathrm{p}=0 \cdot 08)$. No difference was found between gall bladder volume of patients with $(73.0(18.1) \mathrm{ml})$ and without $(72.6(21.0) \mathrm{ml})$ inflammatory bowel disease. No relation was found between fasting gall bladder volume and biochemical disturbances of liver enzymes (data not shown).

The upper limit of fasting gall bladder volume in our entire control population (healthy plus disease controls), calculated by taking the mean $+2 \mathrm{SD}$ of all control subjects $(n=69)$, was $51 \mathrm{ml}$. A fasting gall bladder volume $>51 \mathrm{ml}$ was found in 13 of 24 patients with PSC (five of five with late and eight of 19 with early stage disease), one of 13 PBC, three of 18 controls with liver cirrhosis, 0 of 15 ulcerative colitis controls, and one of 23 healthy controls. As this study was not conducted prospectively, reliable figures on sensitivity and specificity of gall bladder enlargement cannot be provided. However, it is clear from our data that the finding of a large gall bladder $(>50 \mathrm{ml})$ is common in patients with PSC $(>50 \%)$, rare in controls with other liver diseases, and exceptional in healthy controls and patients with ulcerative colitis.

GALL BLADDER EMPTYING

Figure 3 shows the results of postprandial gall bladder emptying. Residual gall bladder volume was significantly enlarged in patients with PSC $(16.0(4.7) \mathrm{ml}$, median $5.7 \mathrm{ml})$ compared with healthy controls $(3.2(0.7) \mathrm{ml}$, $\mathrm{p}<0.05)$ but not with patients with PBC $(7.5$ $(2 \cdot 3) \mathrm{ml})$. However, residual volumes as a percentage of fasting volume in patients with
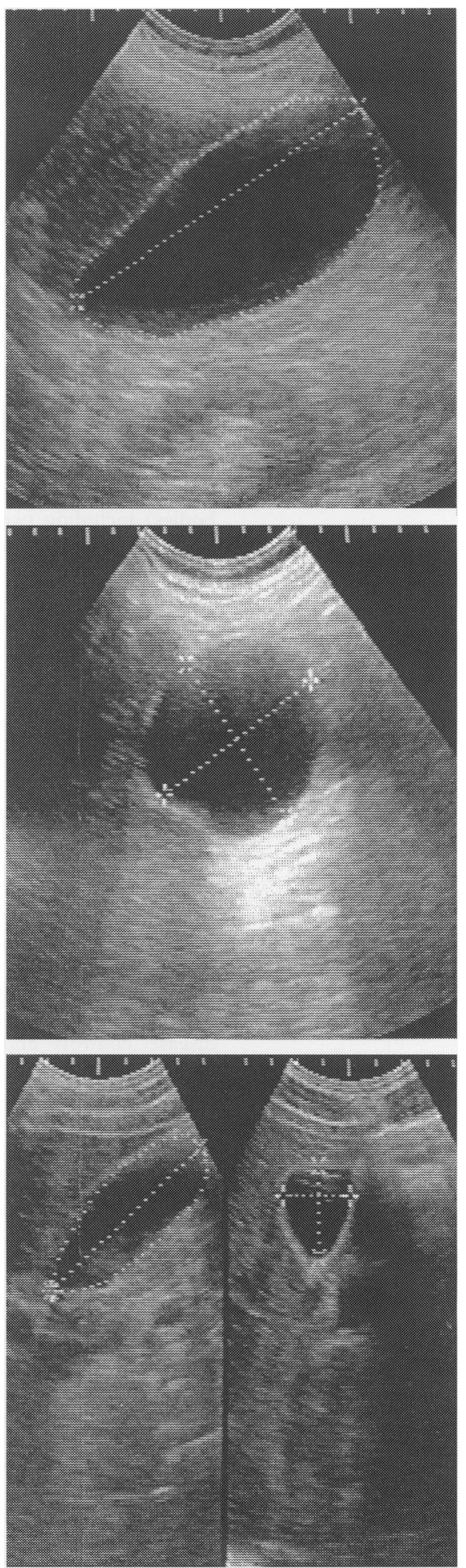

Figure 2: Ultrasonographic appearance (longitudinal and transversal scans) of a large gall bladder in a patient with PSC (above and middle; length $12.3 \mathrm{~cm}$, width $6.6 \mathrm{~cm}$, height $6.0 \mathrm{~cm}$, volume $253.0 \mathrm{ml}$ ) and a healthy control (below; length $7.2 \mathrm{~cm}$, width $2.5 \mathrm{~cm}$, height $2.8 \mathrm{~cm}$, volume $26 \cdot 2 \mathrm{ml}$ ). 


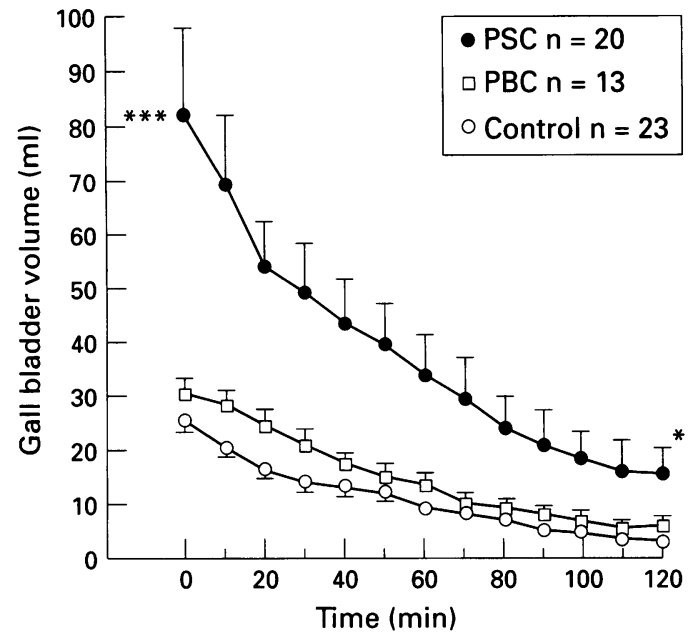

Figure 3: Fasting and postprandial gall bladder volumes in patients with PSC (O, $n=20$, patients with $>4 \mathrm{~mm}$ gall bladder wall thickness excluded), $P B C(\square, n=13)$, and healthy controls $(\mathrm{O}, n=23)$. Fasting volume was significantly increased in patients with PSC compared with patients with PBC and healthy controls ( $* * * p<0.0005)$. Residual volume was significantly greater in patients with PSC compared with healthy controls $\left({ }^{\star} p<0.05\right)$.

PSC $(17 \cdot 5(3 \cdot 7 \%)$, patients with PBC $(23.6$ $(7 \cdot 1) \%)$, and healthy controls $(12 \cdot 7(2 \cdot 3) \%)$ were comparable.

\section{Discussion}

This study confirms our preliminary finding that gall bladder volume is often enlarged in patients with PSC. ${ }^{8}$ According to the size of the gall bladder, patients can be divided into three subgroups. A majority of patients (54\%) with a large or very large gall bladder $(>50 \mathrm{ml})$, a group with a gall bladder volume up to $50 \mathrm{ml}$ $(29 \%)$, and a group of patients with thickening of the gall bladder wall and a normal gall bladder volume $(17 \%)$. Irregular thickening of the gall bladder wall, in the absence of gallstones or portal hypertension, has previously been reported in PSC by Brandt et al. ${ }^{13}$

Patients with ulcerative colitis, not complicated by PSC, had a gall bladder volume comparable with normal subjects and patients with PBC or liver cirrhosis due to other causes had only a slight increase of gall bladder volume. In line with previous studies, gall bladder volume tended to be larger in patients with liver cirrhosis, especially in those without portal hypertension. ${ }^{2021}$

Although gall bladder enlargement is known to occur in other disorders such as distal biliary obstruction, ${ }^{22}$ acromegaly, ${ }^{23}{ }^{24}$ octreotide treatment, ${ }^{23} 24$ obesity, ${ }^{25}{ }^{26}$ gall stone disease, ${ }^{27} 28$ chronic pancreatitis, ${ }^{29}$ truncal vagotomy, ${ }^{30}$ and pregnancy, ${ }^{31}$ there is generally only a moderate increase of gall bladder volume and extremely increased gall bladder volume $(>100 \mathrm{ml})$ as in some of our patients with PSC is not found.

Our data suggest that in patients with disturbed liver biochemistry of unknown aetiology the suspicion of PSC should be raised if a very large gall bladder $(>50 \mathrm{ml})$ is found at ultrasonography. In general practice this finding may be especially helpful in patients with ulcerative colitis, of whom about $5 \%$ develop PSC. ${ }^{1}$ Although a thickened gall bladder wall can also point at PSC, this finding is non-specific and therefore not very useful in the differential diagnosis. Fasting gall bladder volume measurement can be performed when ultrasonography of the liver is indicated for abnormal liver biochemistry. In general practice the volume can easily be calculated with the ellipsoid formula $(0.52 \times$ maximum length $\times$ maximum width $\times$ maximum height). ${ }^{17}$ In our opinion the finding of an enlarged gall bladder and disturbed liver biochemistry in otherwise asymptomatic patients with ulcerative colitis justifies invasive procedures (liver biopsy, ERC) to confirm or rule out the diagnosis of PSC. With this policy asymptomatic patients may be diagnosed earlier and appropriate treatment can be started at an earlier disease stage. Although a very large gall bladder was highly suggestive for the diagnosis of PSC in our population, one should realise that this abnormality was found in not more than $42 \%$ of early stage disease patients. This indicates that the sensitivity of this test is rather low in this category of patients and that a normal sized gall bladder does not exclude the diagnosis.

A direct explanation for enlargement of the gall bladder in patients with PSC cannot be derived from our data. The gall bladder volume tended to be larger in patients with late stage disease than in patients with early stage disease. Mechanical obstruction of the distal common bile duct, as in pancreatic cancer, or the cystic duct as in the case of an impacted gall stone are known causes for gall bladder enlargement. As PSC is a disease involving the bile ducts and sometimes the cystic duct, ${ }^{10} 13$ the Oddi sphincter, ${ }^{32}$ or the pancreas, ${ }^{33}$ an obstruction of biliary outflow seems the most obvious explanation. However, this theory is poorly supported by our findings. None of the patients with PSC was jaundiced at the time of the study and only moderate cholestasis was found. Furthermore, no difference in gall bladder volume was found between patients with bile duct strictures distal from the cystic duct and those with merely proximal bile duct strictures. Placement of an endoprosthesis (bypassing the Oddi sphincter) in a patient with a dominant stricture of the common bile duct had no influence on the large gall bladder volume. Finally, all patients showed normal meal induced gall bladder emptying suggesting patency of the cystic duct and common bile duct and normal function of the Oddi sphincter. On the other hand, the above mentioned arguments do not exclude the presence of chronic increased biliary pressure. Even in the absence of major strictures, the compliance of the biliary tract may be reduced due to inflammatory changes in the bile duct wall. To confirm this theory it would be necessary to perform endoscopic manometry of the Oddi sphincter and the common bile duct, a procedure linked with considerable risks, probably even more so in patients with PSC. ${ }^{34}$ Alternatively, biliary tract pressures could be measured during laparotomy when patients are referred for liver transplantation. 
Alternatively, an intrinsic defect of the gall bladder itself may be responsible for the enlargement of gall bladder volume in PSC. It has been suggested that the gall bladder is involved in the inflammatory process in patients with PSC. ${ }^{10} 1335$ One study has shown an inflammatory response in the gall bladder very similar to that found in the liver in patients with PSC. ${ }^{13}$ This finding is in line with the concept that, contrary to PBC, in PSC the entire biliary tree can be affected. ${ }^{36}$ We found overt gall bladder wall abnormalities in four patients, all with a normal gall bladder volume. In most of the other patients the gall bladder wall was normal but gall bladder volume increased. It can be hypothesised that these patients have a gall bladder with a dysfunctional mucosa leading to decreased bile concentration or increased secretion and subsequent increase of gall bladder volume. Theoretically, if the entire gall bladder wall is involved, thickening of the wall will prevent enlargement of the gall bladder. The concept of poorly concentrated, less viscous bile may also explain why gall bladder emptying is efficient even in patients with extrahepatic bile duct stricturing. Further studies are needed to clarify whether dysfunction of the gall bladder mucosa plays a part in the enlargement of the gall bladder in PSC.

Finally, mediators of gall bladder motility such as acetylcholine ${ }^{37}$ and cholecystokinin ${ }^{38}$ may be modified during cholestasis. None of our patients was known to have autonomic neuropathy. Furthermore, the rapid and efficient gall bladder emptying in response to a meal suggests normal neurohormonal regulation of gall bladder motility in patients with PSC.

In conclusion, apart from thickening of the gall bladder wall, patients with PSC often present with enlargement of the gall bladder. Sonographic determination of fasting gall bladder volume may be a useful, non-invasive, and easy to perform tool in the evaluation of patients suspected of having PSC, particularly patients with ulcerative colitis with disturbed liver biochemistry.

This work was supported by a grant of The Royal Netherlands Academy of Arts and Sciences to KJ v E. This work has been presented as a poster during the Digestive Disease Week in San presented as a poster during the Digestive Disease Week in San
Diego, USA, May 1995, and published in abstract form in Gastroenterology.

1 Ludwig J, Larusso NF, Wiesner RH. The syndrome of primary sclerosing cholangitis. Prog Liver Dis 1990; 9: 555-66.

2 Aubertin J, Prat F, Fritsch J, Choury AD, Etienne JP. Diagnostic ERCP and its complications. Endoscopy 1993; 25: 343-4.

3 Chuah SY, Moody GA, Wicks ACB, Mayberry JF. A nationwide survey of liver biopsy. Is there a need to increase resources, manpower and training ? Hepatogastroenterology 1994; 41: 4-8.

4 O'Brien CB, Senior JR, Arora-Mirchandani R, Batta AK, Salen G. Ursodeoxycholic acid for the treatment of primary sclerosing cholangitis: a 30-month pilot study. Hepatology 1991; 14: 838-47.

5 Beuers U, Spengler U, Kruis W, Aydemir Ü, Wiebecke B, Heldwein W, et al. Ursodeoxycholic acid for treatment of primary sclerosing cholangitis: a placebo controlled trial. Hepatology 1992; 16: 707-14.

6 Stiehl A, Walker S, Stiehl L, Rudolph G, Hofmann WJ, Theilmann L. Effect of ursodeoxycholic acid on liver and bile duct disease in primary sclerosing cholangitis. A 3 -year pilot study with a placebo-controlled study period. 3-year pilot study with a placet
7 Poupon RE, Poupon R, Balkau B, and the UDCA-PBC Study Group. Ursodiol for the long-term treatment of primary biliary cirrhosis. $N$ Engl $f$ Med 1994; 330: 1342-7.

8 Van de Meeberg PC, Van Erpecum KJ, Samsom M Stolk MFJ, Portincasa P, Akkermans LMA, et al. Antroduodenal and gallbladder (GB) motility in primary sclerosing cholangitis (PSC): effects of ursodeoxycholic ? בid. Gastroenterology 1994; 106: A1001.

9 Doyle 'TC, Roberts-Thomson IC. Radiologic features of sclerosing cholangitis. Australas Radiol 1983; 27: 163-6.

10 Scully RE, Mark EJ, McNeely BE. Case records of the Massachussetts General Hospital (case 6-1982). $N$ Engl fMed 1982; 306: 349-58.

11 MacCarty RL, Larusso NF, Wiesner RH, Ludwig J. Primary sclerosing cholangitis: findings on cholangiography and pancreatography. Radiology 1983; 149: 39-44

12 Rohrmann CA, Ansel HJ, Freeny PC, Silverstein FE, Protell RL, Fenster LF, et al. Cholangiographic abnormalities in patients with inflammatory bowel disease. Radiology 1978; 127: 635-41.

13 Brandt DJ, MacCarty RL, Charboneau JW, Larusso NF, Wiesner RH, Ludwig J. Gallbladder disease in patients with primary sclerosing cholangitis. AfR Am f Roentgenol 1988; 150: 572-4.

14 Van Erpecum KJ, VanBerge Henegouwen GP, Stolk MFJ, Hopman WPM, Jansen JBMJ, Lamers CBHW. Effects of ursodeoxycholic acid on gallbladder contraction and cholecystokinin release in gallstone patients and normal subjects. Gastroenterology 1990; 99: 836-42.

15 Palasciano G, Portincasa P, Belfiore A, Baldassarre G, Albano O. Opposite effects of cholestyramine and loxiglumide on gallbladder dynamics in humans. Gastroenterology 1992; 102: 633-9.

16 Everson GT, Breverman DZ, Johnson ML, Kern F. A critical evaluation for the study of gallbladder volume and contraction. Gastroenterology 1980; 79: 40-6.

17 Dodds WJ, Groh WJ, Darweesh RMA, Lawson TL, Kishk SMA, Kern MK. Sonographic measurement of gallbladder volume. Aff Am $\mathscr{f}$ Roentgenol 1985; 145: 1009-11.

18 Stolk MFJ, Van Erpecum KJ, VanBerge Henegouwen GP, Kesselring OFHW, Hopman WPM. Ultrasonography for Kesselring OFHW, Hopman WPM. Ultrasonography for parison of sum-of-cylinders method with ellipsoid areaparison of sum-of-cylinders method with ellipsoid arealength

19 Acalovschi M, Von Ritter C, Miquel JF, Pauletzki J, Meyer G, Paumgartner G, et al. Accuracy of sonographic gallbladder volume determinations in man. Gastroenterology 1994; 106: A332.

20 Acalovschi M, Badea R, Dumitrascu DL. Gall bladder emptying in response to a fatty meal in patients with liver cirrhosis: a sonographic study. Eur $\mathcal{f}$ Gastroenterol Hepatol 1994; 6: 437-41.

21 Toni R, Bolondi L, Gaiani S, Re G, Calabrese L, Cavalli G et al. Accessory ultrasonographic findings in chronic liver disease: diameter of splenic and hepatic arteries, fasting
gallbladder volume, and course of left portal vein. $\mathcal{f}$ Clin gallbladder volume, and cours
Ultrasound 1985; 13: 611-8.

22 Hermann RE, Cooperman AV. Cancer of the pancreas. $N$ Engl f Med 1979; 301: 482-5.

23 Stolk MFJ, Van Erpecum KJ, Koppeschaar HPF de Bruin WI, Jansen JBMJ, Lamers CBHW, et al. Postprandial gall bladder motility and hormone release during intermittent and continuous subcutaneous octreotide treatment in acromegaly. Gut 1993; 34: 808-13.

24 Hopman WPM, Van Liessum PA, Pieters GFFM, Jansen JBMJ, Lamers CBHW, Smals AGH, et al. Postprandial gallbladder motility and plasma cholecystokinin at regular time intervals after injection of cholecystokinin at regular time intervals after injection of octreotide in acromegalics

25 Palasciano G, Serio G, Portincasa P, Palmieri V, Fanelli M, Velardi $\mathrm{A}$, et al. Gallbladder volume in adults, and relationship to age, sex, body mass index, and gallstones: a sonographic population study. Am $\mathcal{F}$ Gastroenterol 1992; 87: 493-7.

26 Kucio C, Besser P, Jonderko K. Gallbladder motor function in obese versus lean females. F Clin Nutr 1988; 42: $121-4$.

27 Van Erpecum KJ, VanBerge Henegouwen GP, Stolk MFJ, Hopman WPM, Jansen JBMJ, Lamers CBHW. Fasting gallbladder volume, postprandial emptying and gallacla subjects. F Hepatol 1992; 14: 194-202.

28 Portincasa $P$ Di Ciaula A Baldassarre G, Palmieri V, Gentile A, Cimmino A, et al. Gallbladder motor function in gallstone patients: sonographic and in vitro studies on the role of gallstones, smooth muscle function and gallbladder wall inflammation. $\mathcal{F}$ Hepatol $1994 ; 21: 430-40$.

29 Meguro T, Shimosegawa T, Kashimura J, Kikuchi Y, Koizumi M, Toyota T. Gallbladder emptying to endogenous and exogenous stimulation in chronic pancreatitis patients. Am F Gastroenterol 1994; 89: 225-31.

30 Masclee AAM,Jansen JBMJ, Driessen WMM, Geuskens LM Lamers CBHW. Effect of truncal vagotomy on cholecystokinin release, gallbladder contraction, and gallbladder sensitivity to cholecystokinin in humans. Gastroenterology 1990; 98: 1338-44.

31 Kern F, Everson GT, DeMark B, McKinley C, Showalter R, Erfling W, et al. Biliary lipids, bile acids, and gallbladder function in the human female; effects of pregnancy and the ovulatory cycle. F Clin Gastroenterol 1981; 68: the ovulato. 
32 Muller EL, Miyamoto T, Pitt HA, Longmire WP. Anatomy of the choledochopancreatic duct junction in primary sclerosing cholangitis. Surgery 1985; 97: 21-7.

33 Lindstrom E, Bodemar G, Ryden BO, Ihse I. Pancreatic ductal morphology and exocrine function in primary sclerosing cholangitis. Acta Chir Scand 1990; 156: 451-6.

34 Hawes RH, Lehman GA. Complications of sphincter of Oddi manometry and their prevention Gastrointest Endoscopy Clinics of North America 1993; 3: 107-18.

35 Carroll BA, Oppenheimer DA. Sclerosing cholangitis: sonographic demonstration of bile duct wall thickening. $A f R$ Am ₹ Roentgenol 1982; 139: 1016-8.
36 Wiesner RH, Ludwig J, Larusso NF, MacCarty RL. Diagnosis and treatment of primary sclerosing cholangitis. Semin Liver Dis 1985; 5: 241-53.

37 Hopman WPM, Jansen JBMJ, Rosenbusch G Lamers CBHW. Cephalic stimulation of gallbladder contraction in humans: role of cholecystokinin and the cholinergic system. Digestion 1987; 38: 197-203.

38 Beglinger C, Hildebrand P, Adler G, Werth B, Luo $\mathrm{H}$ Delco F, et al. Postprandial control of gallbladder contraction and exocrine pancreatic secretion in man. Eur f Clin Invest 1992; 22: 827-34. 